\title{
'Pulsed' Immunosuppressive Therapy in the Treatment of Immunologically Induced Corneal and Scleral Disease
}

\author{
PAUL A. R. MEYER, PETER G. WATSON, WENDY FRANKS and PAUL DUBORD* \\ London, Cambridge and Vancouver
}

\begin{abstract}
Summary
'Pulsed' immunosuppressive therapy, using methylprednisolone with or without cyclophosphamide, has effectively controlled severe destructive corneal and scleral disease that had been unresponsive to oral steroids. Thirty-seven patients have been treated in this manner and the results, complications and possible mechanism of action are discussed.
\end{abstract}

The corneal melting conditions and necrotising scleritis can rapidly destroy vision; the former by corneal opacification or perforation and the latter by causing uveitis, glaucoma, hypotony, cataract, retinal detachment and optic atrophy. Many of these consequences can be avoided or reversed by immediate and effective treatment.

So disastrous are these conditions that a variety of treatments has been tried. Topical non-steroidal anti-inflammatory agents or steroids are usually ineffective ${ }^{l}$ and perforation of the globe has been reported to follow the injection of subconjunctival steroids. ${ }^{2}$ Some patients respond to systemic non-steroidal anti-inflammatory agents or high-dose oral steroids ${ }^{1.2}$ but others respond to neither. Surgery is never helpful unless the condition has already been treated because the destructive changes may continue in the host and can also affect the margins of a graft.

Steroids have long been known to ameliorate disorders of the immune system ${ }^{3}$ and to prolong allograft survival. ${ }^{4}$ The practice of using massive intravenous doses to supplement more moderate oral therapy emerged empirically in the late 1960 s and acquired experimental respectability when skin allograft survival in rats was shown to be prolonged by intravenous methylprednisolone, supplementing a low-dose oral regime..$^{5}$

It is now known that 'pulsed' steroid therapy can abort the rejection of renal allografts $^{6.7}$ and moderate the course of glomerulonephritis, ${ }^{8.9}$ SLE, ${ }^{10.11 .12}$ dermatomyositis, ${ }^{13.14}$ polyarteritis nodosa, ${ }^{15}$ rheumatoid arthritis ${ }^{16}$ and inflammatory eye disease. ${ }^{17}$

The immuno-suppressive effect of the alkylating agent, cyclophosphamide, arises from its capacity to inhibit lymphocyte mitosis, exemplified by its efficacy in the control of Hodgkin's lymphoma. ${ }^{18.19}$ It has been used to treat such immunological disorders as rheumatoid arthritis, ${ }^{21.21}$ Wegener's gran-

From: Moorfields Eye Hospital, City Road, London. Addenbrooke's Hospital, Cambridge.

* University of British Columbia, Vancouver.

Correspondence to: Mr. P. G. Watson, Department of Ophthalmology, Addenbrooke`s Hospital, Cambridge CB2 2QQ. 
ulomatosis, ${ }^{22}$ localised orbital vasculitis, ${ }^{23}$ and Mooren's ulcer. ${ }^{24}$

The folic acid antagonist methotrexate has also been used to manage. Mooren's ulcer, ${ }^{24}$ and peripheral corneal melts have been successfully treated with the purine antagonist, azathioprine. ${ }^{25}$

Many patients with severe, destructive corneo-scleral disease that is resistant to conventional therapy have been found to respond to high intravenous doses ('pulses') of methylprednisolone, often supplemented by cyclophosphamide. ${ }^{1,17}$ Corneal or scleral defects may then be successfully covered by lamellar grafts.

Cyclophosphamide and 'pulsed' methylprednisolone may be hazardous treatments and deaths have been reported during or shortly after methylprednisolone 'pulses. ${ }^{26,27}$ However, necrotising scleritis and the corneal melting disorders are inevitably destructive to the eye. It was hoped that 'pulsed' steroids and cyclophosphamide could control unresponsive disease and reduce or eliminate the need for prolonged, oral courses of these toxic drugs. This paper describes a preliminary uncontrolled assessment of this therapy and the results, complications and mechanisms of action are discussed.

\section{Material and Methods}

Patients (Table I)

Thirty-seven patients with corneal destructive disease or scleritis were treated with 'pulsed' immunosuppressive therapy between 1981 and 1986, of whom 15 were males and 23 were females. Their follow-up ranged from 6 months to 3 years. They were seen as secondary referrals at the Scleritis Clinic of Moorfields Eye Hospital, City Road, London; Addenbrooke's Hospital, Cambridge; and The University Eye Clinic, Vancouver (Mr. Dubord).

The ocular and systemic conditions from which the patients were suffering are categorised in Table I. Four patients had both pre- and post-equatorial scleritis. Three of them (two with Wegener's granulomatosis and one without discernable systemic pathology), whose anterior disease was inactive at the time of 'pulse' therapy, are classified as posterior scleritis. The remaining patient had necrosis of his entire superior anterior segment to behind the equator and is categorised as necrotising anterior scleritis.

Patients with corneal destructive disease had all failed to respond to topical steroids prior to their referral. Topical steroids were never used by us to treat scleral disease, but every patient with diffuse or nodular scleritis had received a non-steroidal anti-inflammatory agent.

All but four of the subjects had also been unresponsive to, or intolerant of, a two-week course of oral prednisolone (starting at $60 \mathrm{mg} /$ day and reducing to a maintenance dose of $10 \mathrm{mg} / \mathrm{day}$ ). The four patients whose aggressive disease demanded immediate intervention suffered from Moorens ulcer, diffuse anterior scleritis, necrotising anterior scleritis, and posterior scleritis respectively.

Prior to treatment, the incidence of anterior uveitis (cells and flare in the anterior chamber and occasional posterior synechiae) was as follows:

Table I. Patients

\begin{tabular}{|c|c|c|c|c|c|c|c|c|c|}
\hline \multirow{2}{*}{\multicolumn{2}{|c|}{$\begin{array}{l}\text { Type of corneal or } \\
\text { scleral disease }\end{array}$}} & \multirow[b]{2}{*}{ No } & \multirow[b]{2}{*}{$M: F$} & \multirow[b]{2}{*}{ Rheumatoid } & \multicolumn{3}{|c|}{ Associated systemic or local pathology } & \multirow[b]{2}{*}{$\begin{array}{l}\text { Cataract } \\
\text { extraction }\end{array}$} & \multirow[b]{2}{*}{ None } \\
\hline & & & & & $\begin{array}{c}\text { Wegener's } \\
\text { granulomatosis }\end{array}$ & $\begin{array}{c}\text { Relapsing } \\
\text { polychnondritis }\end{array}$ & $\begin{array}{l}\text { Systemic } \\
\text { vasculitis }\end{array}$ & & \\
\hline $\begin{array}{l}\text { Corneal } \\
\text { guttering }\end{array}$ & $\begin{array}{l}\text { Mooren's } \\
\text { ulcer } \\
\text { Peripheral } \\
\text { corneal } \\
\text { melt }\end{array}$ & 6 & $4: 2$ & 5 & & & & & 6 \\
\hline $\begin{array}{l}\text { Anterior } \\
\text { scleritis }\end{array}$ & $\begin{array}{l}\text { Diffuse } \\
\text { Nodular } \\
\text { Necrotising }\end{array}$ & $\begin{array}{r}6 \\
3 \\
13\end{array}$ & $\begin{array}{l}4: 2 \\
1: 2 \\
6: 7\end{array}$ & $\begin{array}{l}2 \\
4\end{array}$ & 1 & 1 & 1 & 2 & $\begin{array}{l}3 \\
2 \\
3\end{array}$ \\
\hline $\begin{array}{l}\text { Posterior } \\
\text { scleritis }\end{array}$ & & 4 & $1: 3$ & & 2 & & 2 & & 2 \\
\hline TOTAL & & 37 & & 11 & 3 & 1 & 4 & 2 & 16 \\
\hline
\end{tabular}


Peripheral corneal melts

$2: 5$

Mooren's ulcer

(Case 6 was seen after a failed

penetrating keratoplasty)

Diffuse anterior scleritis

Nodular anterior scleritis

Necrotising scleritis

Posterior scleritis
$2: 5$

3:6

$2: 3$

$7: 13$

$0: 4$

\section{Treatment}

The management regime was selected following subjective clinical evaluation in patients with severe scleral disease.

Because both drugs are potentially hazardous, all the patients were hospitalised. The results of a full physical examination, blood count, electrolytes, chest X-ray and ECG were considered before a decision was made to administer either drug. In the light of these, the clinician also selected the dose of methylprednisolone $(0.5$ or $1.0 \mathrm{gm})$ and decided whether cyclophosphamide was to be used in addition.

Eight of the 37 patients were treated with methylprednisolone alone and the remainder also received cyclophosphamide. Corneo-scleral defects were later covered by lamellar grafts. Corneal perforations were closed by glueing, followed if necessary by penetrating keratoplasty.

Methylprednisolone and cyclophosphamide were given concurrently:

Methylprednisolone

$500 \mathrm{mg}$ or 1 gram of methylprednisolone was dissolved in $100 \mathrm{ml}$ of 4 per cent dextrose/saline and administered by slow intravenous infusion over one hour.

Cyclophosphamide

A $500 \mathrm{mg}$ bolus of cyclophosphamide was injected into a fast running 4 per cent dextrose/saline infusion. Unless there was a specific contraindication,

oral fluids were encouraged and a further two litres of 4 per cent dextrose/saline (with potassium supplement where appropriate) was administered during the ensuing 24 hours in order to reduce the risk of cyclophosphamide-induced haemorrhagic cystitis. ${ }^{28}$

Where patients were already taking a maintenance dose of steroid and/or cyclophosphamide, this was continued unchanged throughout the 'pulse' therapy. The dose of each was then reduced until a new maintenance regime was established. This constituted the dose below which the disease reactivated: an event that occasionally promoted further 'pulse' therapy. If patients were taking no systemic steroids or cyclophosphamide at the time of their first 'pulse', no maintenance treatment was offered.

\section{Assessment}

The efficacy of treatment was assessed by the following objective findings:

(1) The arrest of disease progression.

(2) Subsidence of inflammation.

(3) Maturation, regression or closure of new vessels.

(4) Reversal of corneal changes (if present).

The relief of pain was also recorded when this was relevant.

\section{Results (Tables II and III)}

'Pulse therapy' resulted in objective improvement in 29:37 patients, of whom 9 underwent corneo-scleral grafting after disease activity had been suppressed. Seven patients responded to methylprednisolone alone, but the remainder also received cyclophosphamide. In the 29 subjects responding to treatment it became possible to reduce maintenance steroid therapy to less than

Table II. Pain relief

\begin{tabular}{llccc}
\hline Type of corneal or scleral disease & No & No of patients with pain & $\begin{array}{c}\text { No of patients with pain } \\
\text { relief 24 hours after } \\
\text { pulsed methylprednisolone }\end{array}$ \\
\hline Corneal guttering & $\begin{array}{l}\text { Mooren's ulcer } \\
\text { Peripheral } \\
\text { corneal melt }\end{array}$ & 6 & 6 & 3 \\
Anterior scleritis & 5 & 0 & 0 \\
& $\begin{array}{l}\text { Diffuse } \\
\text { Nodular }\end{array}$ & 6 & 6 & 6 \\
Posterior scleritis & Necrotising & 13 & 3 & 3 \\
\hline TOTAL & 4 & 13 & 2 \\
\hline
\end{tabular}


Table III. Outcome of therapy

\begin{tabular}{|c|c|c|c|c|c|c|c|}
\hline & & \multirow[b]{3}{*}{ No } & \multicolumn{3}{|c|}{ Patients with objective improvement after pulse therapy } & \multirow{2}{*}{\multicolumn{2}{|c|}{ Failures }} \\
\hline \multirow{2}{*}{\multicolumn{2}{|c|}{ Type of corneal or scleral disease }} & & & Methyl & $\begin{array}{c}\text { Methyl } \\
\text { prednisolone + }\end{array}$ & & \\
\hline & & & prednisolone & cyclophosphamide & + graft & No & Comments \\
\hline \multirow[t]{2}{*}{$\begin{array}{l}\text { Corneal } \\
\text { guttering }\end{array}$} & $\begin{array}{l}\text { Mooren's } \\
\text { ulcer }\end{array}$ & 6 & 0 & 1 & 3 & 2 & $\begin{array}{l}\text { Both responded to } \\
\text { cyclosporin A }\end{array}$ \\
\hline & $\begin{array}{l}\text { Peripheral } \\
\text { corneal melt }\end{array}$ & 5 & 2 & 1 & 1 & 1 & Perforation during treatment \\
\hline \multirow[t]{3}{*}{$\begin{array}{l}\text { Anterior } \\
\text { scleritis }\end{array}$} & Diffuse & 6 & 3 & 2 & 0 & 1 & $\begin{array}{l}\text { Heavily steroid-dependent } \\
\text { after five pulses of methyl } \\
\text { prednisolone }+ \\
\text { cyclophosphamide }\end{array}$ \\
\hline & Nodular & 3 & 0 & 2 & 0 & 1 & Responded to cyclosporin A \\
\hline & Necrotising & 13 & 1 & 4 & 5 & 3 & $\begin{array}{l}\text { i Anterior segment necrosis: } \\
\text { eye became phthysical } \\
\text { ii Additional plasma } \\
\text { exchange required } \\
\text { iii Cyclophosphamide } \\
\text { withheld }\end{array}$ \\
\hline \multicolumn{2}{|c|}{ Posterior scleritis } & 4 & 1 & 3 & 0 & 0 & \\
\hline \multicolumn{2}{|l|}{ TOTAL } & 37 & 7 & 13 & 9 & 8 & \\
\hline
\end{tabular}

$10 \mathrm{mg}$ prednisolone/day. Oral cyclophosphamide never exceeded $150 \mathrm{mg} /$ day.

Although pain characterised anterior scleritis and Mooren's ulceration, it was not experienced by patients with other forms of corneal guttering or by two subjects with posterior scleritis. Its relief by high dose methylprednisolone therapy was unequivocal: it invariably occurred within 24 hours, and was so dramatic that some patients were able to sleep without analgesia for the first time in months (Table II). However, four such patients, suffering respectively from Mooren's ulcer, nodular scleritis and necrotising scleritis $(\times 2)$, did not continue to sustain a remission, even after repeated 'pulses'.

\section{Anterior Scleritis (22 patients)}

Diffuse, nodular and necrotising scleritis all responded equally well, but 5 patients with necrotising scleritis also required lamellar corneo-scleral grafting.

Of 22 patients, one with nodular scleritis and two with necrotising scleritis failed to respond to methylprednisolone alone or in combination with cyclophosphamide. One of the latter was a 74 year old man who presented with necrosis of the entire sclera of the upper globe from the limbus to behind the equator. After 'pulse' therapy and corneo-scleral grafting his pain was relieved, but vision was lost and the eye became phthisical.

\section{Posterior Scleritis (4 patients)}

All the patients in this group responded to therapy with one or both drugs.

\section{Corneal Guttering}

Mooren's ulcer (6 patients)

Of six patients, only one responded to 'pulses' of methylprednisolone and cyclophosphamide alone. Three were successfully managed by lamellar excision and replacement of diseased cornea after two 'pulses' of methylprednisolone and cyclophosphamide 5 days apart. The remaining two patients responded to cyclosporin A therapy.

Other peripheral corneal melts (5 patients)

All five subjects suffered from rheumatoid arthritis and three developed corneal perforations. In two patients these had arisen prior to treatment: the cornea of a 51 year old woman healed after glueing accompanied by 'pulse' therapy, and a 65 year old man required a penetrating keratoplasty. One 63 
year old woman experienced corneal perforation during treatment.

\section{Complications}

Methylprednisolone

Single and repeated doses of $500 \mathrm{mg}$ and $1 \mathrm{gm}$ were well tolerated by most paients. Some suffered from electrolyte disturbances (hypokalaemia), weight gain, sleep disturbance and depression.

A 69 year old woman with posterior scleritis was noted on admission to have an abscess on her nose. One week after her second dose of intravenous methylprednisolone with cyclophosphamide she was readmitted with a staphylococcal pneumonia that responded rapidly to parenteral antibiotics.

One patient in our care, who was not a participant in this study, died within 48 hours of receiving $500 \mathrm{mg}$ methylprednisolone i.v. He was a normotensive 73 year old man with bilateral choroidal effusions complicating systemic sclerosis. He died in clinical left ventricular failure which became complicated by a pneumonia. At post mortem virtually all small arteries showed medial sclerosis and most were obliterated. His death was thought to be a consequence of his disease and not his treatment.

\section{Cyclophosphamide}

Single intravenous doses of cyclophosphamide have been well tolerated, however one 75 year old woman with posterior scleritis complicating rheumatoid arthritis developed agranulocytosis after 2 doses separated by 4 days. She recovered upon withdrawal of cylcophosphamide. Haemorrhagic cystitis did not complicate intravenous cyclophosphamide therapy.

Patients taking oral cyclophosphamide have suffered from hair loss (4 patients), haemorrhagic cystitis ( 3 patients) and pancytopoenia (one patient). The drug had to be withdrawn in 3 cases.

\section{Discussion}

Administration of high-dose intravenous methylprednisolone, alone and in conjunction with cyclophosphamide, controlled destructive corneal and scleral disease. This was the initial means of steroid treatment in four patients with exceptionally severe disease; the remainder had all failed to respond to oral prednisolone. The rarity of such pathology (even in specialist centres), the variety of presentations and the frequent need for surgical intervention precluded controlled comparisons of different treatments, but $25 / 30$ patients ( 83 per cent) experienced dramatic pain relief and 29/37 (78 per cent) entered a period of clinical remission of their disease. Those with Mooren's ulcer responded less consistently than others with corneal melts or with scleritis. The reason for this is unclear, but it does emphasise probable differences in aetiology.

\section{Complications}

Both methylprednisolone and cyclophosphamide had a predictably high incidence of sideeffects, confirming the results of other studies.

The electrolyte disturbances that arose after methylprednisolone were easily reversible, and the psychological symptoms were transient. However, the reports of unpredictable death, during and after infusions of methylprednisolone that had been given with appropriate caution, remain a matter of great concern.

Cyclophosphamide appeared to be safe when given as a single intravenous bolus to a well-hydrated patient, but complications arose when infusions were repeated and during prolonged oral therapy. Of the many known complications (which also include ovarian failure, ${ }^{29}$ azoospermia ${ }^{30}$ pulmonary fibrosis, ${ }^{31}$ haemolytic anaemia, ${ }^{32}$ chromosomal damage, ${ }^{33}$ teratogenesis ${ }^{34,35}$ and malignancy ${ }^{36}$ ), our patients experienced haemorrhagic cystitis ${ }^{28}$ and alopecia. ${ }^{37}$ Most showed some marrow depression (particularly lymphocytopoenia) and macrocystosis. ${ }^{38}$ One patient suffered severe marrow aplasia which was reversed when the drug was withdrawn. The potentially lethal complications of agranulocytosis or marrow aplasia demand careful monitoring of peripheral blood: twice weekly during the inception of therapy and monthly thereafter.

\section{Corticosteroids}

Since most of the patients reported had failed to respond to oral steroids, the effectiveness 
of high intravenous doses is remarkable. In order to understand this, the action of steroids upon the immune system deserves further consideration.

Glucocorticoids may influence the immune response by a central action upon the reticuloendothelial system, or by interference with inflammation:

\section{Central Action}

Steroids alter the turnover of leukocytes and their partition between intra- and extravascular compartments.

After a large steroid infusion the neutrophil leucocyte count rises for 1 to 3 days, reflecting mobilisation of cells from the marrow, an increase in their half-life ${ }^{39}$ and decreased diapedesis. ${ }^{40}$

The lymphocyte count falls to a nadir at 4 hours, returning to normal within 24 hours, ${ }^{5,16,41,42,43}$ because of the loss of T-lymphocytes from the circulation..$^{16.42 .43}$ These accumulate in the bone marrow, ${ }^{44.45}$ where they retain their immunocompetence. ${ }^{45}$ This probably reflects abnormal lymphocyte recirculation in which cells can leave the blood, but are not returned via the thoracic duct. ${ }^{46,47}$

Various T-cell subsets are affected differently, ${ }^{41}$ probably because their ability to metabolise the drug differs ${ }^{48}$ and the ratio of circulating helper/suppressor cells falls. ${ }^{43}$ However, the relevance of this is unclear, since the synovial fluid $\mathrm{H} / \mathrm{S}$ ratio in rheumatoid arthritis is not changed by steroid 'pulses'. ${ }^{49}$

Steroids also inhibit T-cell replication in response to mitogens, and some clones are more sensitive than others. The action of mitogens upon steroid-sensitive clones can be partially restored in vitro by repleting macrophage numbers with cells harvested prior to steroid therapy. ${ }^{41}$ Macrophages and certain T-lymphocytes are known to secrete a T-cell growth factor: its synthesis is triggered by mitogens, but then becomes autonomous, and glucocorticoids inhibit its release into the supernatant of cytotoxic T-cell lines. ${ }^{50}$

\section{Peripheral Action}

The half-lives of prednisolone and methylprednisolone are only $2-4$ hours,${ }^{51}$ and their effect upon lymphocyte recirculation is over within a day. ${ }^{47}$ However, a steroid 'pulse' usually depresses clinical inflammation for as long as a week, prompting the suggestion that bolus steroid therapy impairs the effector component of the inflammatory response. ${ }^{16} \mathrm{In}$ support of this, methylprednisolone does not modify the arteritis that accompanies experimental serum sickness in rabbits, although it aborts the associated fibrinoid necrosis. ${ }^{52}$

Corticosteroids do not affect complement, polymorphonuclear leucocyte chemotaxis and function, or lysosyme, ${ }^{48}$ but their longlived anti-inflammatory affect may result from interference with the action of macrophage inhibitory factor ${ }^{53}$ or the inhibition of prostaglandin synthesis. ${ }^{54}$ Phospholipase A2 catalyses the synthesis of the prostaglandin precurser, arachidonic acid, and steroids are known to induce the synthesis of macrocortin: a phospholipase A2 inhibitor. ${ }^{55}$

\section{High-dose Methylprednisolone}

The discrepancy between the effects of oral prednisolone and intravenous methylprednisolone probably reflects a difference in dosage, rather than in the route of administration, and oral 'pulses' may prove equally effective. . $^{.56}$ Endogenous and synthetic steroids permeate cell membranes, but become reversibly bound to plasma receptors for their transport to the nucleus. ${ }^{48}$ The complement of nuclear steroid receptors in lymphocytes may be increased by mitogens,${ }^{57}$ but the profound effects of methylprednisolone in doses such as were used in this study almost certainly reflects saturation of this system.

A steroid 'pulse' differs from chronic moderate-dose therapy in its ability to 'reset' an aberrant immune response: inhibition of the proliferation of lymphocyte clones, the temporary removal of recirculating T-lymphocytes from the blood and eye and the profound suppression of peripheral inflammation all occur simultaneously.

The discovery that such a manipulation induces long-term remissions may enhance our understanding of destructive corneal and scleral disease. One interpretation is that antigens are exposed or created by mechanical, viral, bacterial or autoimmune injury, and thereafter perpetuated by the inflammatory response. In such a system a 'pulse' may abolish the source of antigen at the same time as it 
suppresses the immune response. When memory T-lymphocytes recirculate, the disease falters in the absence of antigen.

\section{Cyclophosphamide}

This alkylating agent cross-links guanine groups in DNA, interfering with protein synthesis and with mitosis: particularly in cells of the lymphoid series. B-cells are most sensitive, but T-cells are also depleted, ${ }^{21}$ and cellmediated immunity is depressed..$^{58}$

If the suppression of lymphocyte mitosis is an essential part of the action of 'pulsed' corticosteroids, cyclophosphamide should synergise with methylprednisolone. It was our impression that cyclophosphamide did indeed enhance the success with which methylprednisolone therapy achieved and maintained remission, but the lack of matched controls precludes this interpretation of our results.

Where there is no immediate risk to vision, it remains our practice to give every patient with diffuse or nodular scleritis a non-steroidal anti-inflammatory agent (usually flurbiprofen). Although the subjects with corneal guttering in this study had already received topical steroids, we do not normally administer them to patients presenting to us.

Failure to respond to such treatment is an indication for a short course of oral steroids as outlined above. Patients with exceptionally severe destructive corneal or scleral disease may occasionally receive pulsed methylprednisolone (with or without cyclophosphamide) at presentation, but we normally reserve this form of treatment for those who have failed to respond to oral steroids.

The centres participating in this study are attended by over 1,000 patients with inflammatory corneal and scleral disease of presumed auto-immune aetiology. The small number of patients described in this paper reflects the success of non-steroidal antiinflammatory agents and oral steroids. However, such treatments may sometimes be ineffective or insufficient. In these circumstances, 'pulsed' methylprednisolone and cyclophosphamide have been found to be effective and invaluable in the control of an otherwise devastating disease. It has to be recognised, however, that both methylprednisolone and cyclophosphamide are dangerous drugs and should be reserved whenever possible for patients whose disease has failed to respond to conventional therapy.

\section{References}

1 Watson PG: The Nature and the Treatment of Scleral Inflammation. Trans Ophthalmol Soc UK 1982, 102: 257-81.

${ }^{2}$ Watson PG: Diseases of the sclera and episclera. In: Duane TD, Jaeger EA, eds: Clinical Ophthalmology. Philadelphia: Harper and Row, 1987 (In Press).

${ }^{3}$ Fauci AS: Vasculitis: new insights amid old enigmas Am J Med 1979, 67: 916-8.

${ }^{4}$ Silberman H: Dosage of corticosteroids in renal allograft rejection. Am J Surg 1981, 142: 413-5.

${ }^{5}$ Coberg AS, Gray SH, Katz FH, Penn I, Halgrimson C, Starzl TE: Disappearance rates and immunosuppression of itermittent intravenously administered prednisolone in rabbits and human beings. Surg Gynecol Obstet 1970, 131: 933-42.

${ }^{6}$ Bell PRF, Briggs JD, Calman KC, Paton AM, Wood RFM, MacPherson SG, Kyle K: Reversal of acute clinical and experimental organ rejection using large doses of intravenous prednisolone. Lancet 1971 , i: $876-80$.

${ }^{7}$ Orta-Sibu N, Chantler C, Bewick M, Haycock G: Comparison of high-dose intravenous methylprednisolone with low-dose oral prednisolone in acute renal allograft rejection in children. $\mathrm{Br}$ Med J (Clin Res) 1982, 285: 258-60.

${ }^{8}$ Murnaghan K, Vasmant D, Bensman A: Pulse methylprednisolone therapy in severe idiopathic childhood nephrotic syndrome. Acta Paediatr Scand 1984, 73: 733-9.

${ }^{9}$ Tallgren LG: Intravenous pulse methylprednisolone therapy of acute primary crescentic rapidly pregressive glomerulonephritis. Scand J Rheumatol (suppl) 1984, 54: 24-6.

${ }^{10}$ Cathcart ES, Idelson BA, Sheinberg MA, Couser WG: Beneficial effects of methylprednisolone 'pulse' therapy in diffuse proliferative lupus nephritis. Lancet 1976, i: 163-6.

${ }^{11}$ Eyanson S, Passo MH, Aldo-Benson MA, Benson MD: Methylprednisolone pulse therapy for nonrenal lupus erythematosus. Ann Rheum Dis 1980, 39: 377-80.

12 Barron KS, Person DA, Brewer EJ Jr, Beale MG, Robson AM: Pulse methylprednisolone therapy in diffuse proliferative lupus nephritis. J Paediatr 1982, 101: 137-41.

${ }^{13}$ Miller JJ III: Prolonged use of large intravenous steroid pulses in the rheumatic diseases of children. Paediatrics 1980, 65: 989-94.

${ }^{14}$ Yanagisawa T, Sueishi M, Nawata Y, Akimoto T, Nozaki T, Koike T, Tomioka H, Kumagai A: Methylprednisolone pulse therapy in dermatomyositis. Dermatologica 1983, 167: 47-51.

${ }^{15}$ Neild GH and Lee HA: Methylprednisolone pulse therapy in the treatment of polyarteritis nodosa. Postgrad Med J 1977, 53: 382-7. 
${ }^{16}$ Fan PT, Yu DTY, Clements PJ, Fowlston S, Eisman $\mathrm{J}$, Bluestone R: Effect of corticosteroids on human immune response: comparison of one and three daily 1 gram intravenous pulses of methylprednisolone. J Lab Clin 1978, 91: 625-34.

${ }^{17}$ Wakefield D, McCluskey P, Penny R: Intravenous pulse methylprednisolone therapy in severe inflammatory eye disease. Arch Ophthalmol 1986, 104: 847-51.

18 Jacobs EM, Peters FC, Luce JK, Zippin C, Wood DA: Mechlorethamine $\mathrm{HCl}$ and cyclophosphamide in the treatment of Hodgkin's disease and the lymphomas. J Am Med Ass 1968, 20S: 104-10.

${ }^{19}$ Kaplan HS: Hodgkin's disease. Cambridge, Mass: Harvard University Press 1972.

${ }^{20}$ Williams HJ, Reading JC, Ward JR, O'Brien WM: Comparison of high and low dose cyclophosphamide therapy in rheumatoid arthritis. Arthritis Rheum 1980, 23: 521-7.

${ }^{21}$ Horwitz DA: Selective depetion of immunoglobulin bearing lymphocytes by cyclophosphamide in rheumatoid arthritis and SLE. Arthritis Rheum 1974, 17: 363-74.

${ }^{22}$ Fauci AS, Haynes BF, Katz P, Wolff SM: Wegener's granulomatosis: prospective clinical and therapeutic experience with 85 patients for 21 years. Ann Intern Med 1983, 98: 76-85.

${ }^{23}$ Garrity JA, Kennerdell JS, Johnson BL, Ellis LD: Cyclophosphamide in the treatment of orbital vasculitis. Am J Ophthalmol 1986, 102: 97-103.

${ }^{24}$ Foster SC: Systemic immunosuppression for progressive bilateral Mooren's ulcer. Ophthalmology 1985, 92: 1436-9.

${ }^{25}$ Easty DL, Madden P, Jayson MIV, Carter C, Noble BA: Systemic Immunosuppressive Therapy in Marginal Keratolysis. Trans Ophthalmol Soc UK 1978, 98: 410-7.

${ }^{26}$ Freedman MD, Schocket AL, Chapel N, Gerber JG: Anaphylaxis after intravenous methylprednisolone administration. J Am Med Ass 1981, 245: 607-8.

27 Thompson JF, Chalmers DH, Wood RF, Kirkham SR, Morris PJ: Sudden death following high-dose intravenous methylprednisolone. Transplantation 1983, 36: 594-6.

${ }^{28}$ Philips FS, Sternberg SS, Cronin AP, Vidol PM: Cyclophosphamide and urinary bladder toxicity. Cancer Res 1961, 21: 1577-89.

${ }^{29}$ Warne GI, Fairley KF, Hobbs JB, Martin FIR: Cyclophosphamide-induced ovarian failure. New Eng J Med 1973, 289: 1159-62.

${ }^{30}$ Qureshi MSA, Goldsmith HJ, Pennington JH, Cox PE: Cyclophosphamide therapy and sterility. Lancet 1972 ii: $1290-1$.

${ }^{31}$ Patel AR, Shah PC, Rhee HL, Sassoon H, Rao KP: Cyclophosphamide therapy and interstitial pulmonary fibrosis. Cancer 1976, 38: 1542-9.

32 Yonet HM, Vigliano EM, Horowitz HI: Acute haemolytic anaemia associated with administration of alkylating agents: report of two cases due to cyclophosphamide and review of the literature. Am J Med Sci 1967, 254: 48-55.
${ }^{33}$ Nasjleti CE and Spencer HH: Chromosome polyploidization in human leukocyte cultures treated with streptonigrin and cyclophosphamide. Cancer (phla.) 1967, 20: 31-5.

${ }^{34}$ Toledo TM, Harper RC, Moser RH: Fetal effects during cyclophosphamide and irradiation therapy. Ann Int Med 1971, 74: 87-91.

${ }^{35}$ Greenberg LH, Verdes P, Tanaka KR: Congenital anomalies probably induced by cyclophosphamide. J Am Med Ass 1964, 188: 423-6.

${ }^{36}$ Marshall V: Premalignant and malignant skin tumours in immunosuppressed patients. Transplantation 1974, 17: 272-5.

${ }^{37}$ Drugs and Ther Bull 1978, 16: 77.

${ }^{38}$ Klippel JH and Decker JL: Relative macrocytosis in cyclophosphamide and azathioprine therapy. $J$ Am Med Ass 1974, 229: 180-1.

${ }^{39}$ Bishop CR, Athens JW, Boggs DR, Warner HR, Cartwright GE, Wintrobe MM: Leukokinetic studies: XIII. A non-steady state kinetic evaluation of the mechanism of cortisone-induced granulocytosis. J Clin Invest 1968, 47: 249-60.

${ }^{40}$ Ebert RN and Barclay WR: Changes in connective tissue reaction induced by cortisone. Ann Int Med 1952, 37: 506-18.

${ }^{41}$ Fauci AS and Dale DC: The effect of in vivo hydrocortisone on subpopulations of human lymphocytes. J Clin Invest 1974, 53: 240-6.

${ }^{42}$ Yu DTY, Clements PJ, Paulus HE, Peter JB, Levy J, Barnett EV: Human lymphocyte subpopulations: effect of corticosteroids. J Clin Invest 1974, 53: 565-71.

${ }^{43}$ Silverman ED, Myones BL, Miller JJ: Lymphocyte subpopulation alterations induced by intravenous megadose pulse methylprednisolone. $J$ Rheumatol 1984, 11: 287-90.

${ }^{44}$ Cohen JJ: Thymus-derived lymphocytes sequestrated in bone marrow of hydrocortisone-treated mice. J Immunol 1972, 108: 841-4.

${ }^{45}$ Fauci AS: Mechanism of corticosteroid action on lymphocyte subpopulations: I. Redistribution of circulating $\mathrm{T}$ and $\mathrm{B}$ lymphocytes to the bone marrow. Immunology 1975, 28: 669-80.

${ }^{46}$ Spry CJF: Inhibition of lymphocyte recirculation by stress and corticotrophin. Cell Immunol 1972, 4: 86-92.

${ }^{47}$ Fauci AS and Dale DC: The effect of hydrocortisone on the kinetics of normal human lymphocytes. Blood 1975, 46: 235-43.

${ }^{48} \mathrm{Katz}$ P: Immunosuppressive therapy. Adv Int Med 1984, 29: 167-92.

${ }^{49}$ Bertouch JV, Roberts-Thomson PJ, Smith MD, Woodruff TG, Brooks PM, Bradley J: Methylprednisolone infusion therapy in rheumatoid arthritis patients: the effect on synovial fluid lymphocyte subsets and inflammatory indices. Arthritis Rheum 1986, 29: 32-8.

${ }^{50}$ Gillis S, Crabtree GR, Smith KA: Glucocorticoidinduced inhibition of T-cell growth factor production I. The effect on mitogen-induced lymphocyte proliferation. J Immunol 1979, 123: 1624-31.

${ }^{51}$ Goodman Gilman A, Goodman LS, Rall TW, 
Murad F (eds) The Pharmacological Basis of Therapeutics: 7th edn. New York. Macmillan, 1985: 1696.

52 Neild GH, Ivory K, Gwyn Williams D: Effects of high-dose i.v. steroid (pulse) therapy on acute serum sickness in rabbits. Br J Exp Path 1982, 63: 606-14.

${ }^{53}$ Balow JE and Rosenthal AS: Glucocorticoid suppression of macrophage migration inhibitory factor. J Exp Med 1973, 137: 1031-41.

${ }^{54}$ Kantrowitz F, Robinson DR, McGuire MB, Levine $\mathrm{L}$ : Corticosteroids inhibit prostaglandin production by rheumatoid synovia. Nature 1975, 258: 737-9.
${ }^{55}$ Blackwell GJ, Carnuccio R, DiRosa M, Flower RJ, Parente L, Persico P: Macrocortin: a polypeptide causing the anti-phospholipase effect of glucocorticoids. Nature 1980, 287: 147-9.

56 Lancet (editorial) Prednisolone pulses in collagen disease: grammes or milligrammes? Lancet 1983, i: $280-1$.

${ }^{57}$ Smith KA, Crabtree GR, Kennedy SJ, Munck A: Glucocorticoid receptors and sensitivity of mitogen stimulated and unstimulated lymphocytes. Nature 1977, 267: 523-6.

${ }^{58}$ Fauci AS, Wolff SM, Johnson JS: Effect of cyclophosphamide upon the immune response in Wegener's granulomatosis. N Engl J Med 1971, 285: 1493-6. 